\title{
The Effect of Topical Corticosteroid Time of Application on Fibroblast and Type III Collagen Expression in Oryctolagus cuniculus with Deep Dermal Burn Wound (As an Indicator for the Best Time to Start Topical Corticosteroid Application in Preventing Hypertrophic Scar)
}

\author{
Loelita Lumintang ${ }^{*}$ (iD), I Made Suka Adnyana, Agus Roy Hamid ${ }^{1}$, Hendra Sanjaya ${ }^{1}$, Nyoman Golden², Putu Astawa ${ }^{3}$, \\ Made Darmajaya ${ }^{4}$, I Wayan Juli Sumadi ${ }^{5}$ \\ ${ }^{1}$ Department of Surgery, Division of Plastic Reconstructive and Aesthetic Surgery, Faculty of Medicine, Udayana University, \\ Sanglah General Hospital, Bali, Indonesia; ${ }^{2}$ Department of Surgery, Neurosurgery Division, Faculty of Medicine, Udayana \\ University, Sanglah General Hospital, Bali, Indonesia; ${ }^{3}$ Orthopedic and Traumatology Department, Faculty of Medicine, \\ Udayana University, Sanglah General Hospital, Bali, Indonesia; ${ }^{4}$ Department of Surgery, Pediatric Surgery Division, Faculty of \\ Medicine, Universitas Udayana, Sanglah General Hospital, Bali, Indonesia; ${ }^{5}$ Department of Anatomical Pathology, Faculty of \\ Medicine, Udayana University, Sanglah General Hospital, Bali, Indonesia
}

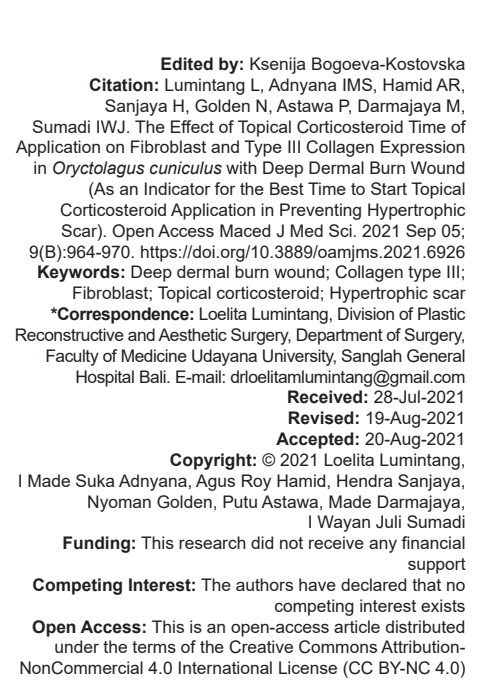

\section{Introduction}

Hypertrophic scar is an unsolved abnormal wound that is not only esthetically not pleasing but can also disrupt skin function (pruritus, contracture, deformity, and/or pain). This type of scar often triggers psychological problems, especially if it appears in a very conspicuous area. The incidence of hypertrophic scars due to deep dermal burns wound is up to $70-90 \%$. Pathologically, it characterized by the accumulation of

\section{Abstract}

BACKGROUND: Hypertrophic scar is an abnormal scar that causes physical deteriorations, psychological problems and esthetic issues. An excessive number of fibroblasts and collagen III expressions are histopathology indicators for the hypertrophic scar. The role of topical corticosteroids in suppressing inflammation and hypergranulation had widely demonstrated in the previous studies. However, there is no study related to the application of topical corticosteroids as prevention of hypertrophic scars from burn wound found.

AIM: Hence, this study aimed to examine the evidence of the effects of corticosteroid topical in decreasing the number of fibroblasts and type III collagen expression and the best time to start its application in preventing hypertrophic scars

METHODS: This randomized experimental post-test only study involved 54 deep dermal burn wounds on the ventra ear of female Oryctolagus cuniculus that distributed into three groups based on the healing phases. Each group consisted of treatments and controls. Corticosteroid topical application on the first treatment group (inflammatory phase group), the second group (proliferation phase group), and the third group (remodeling phase group) was started on day 3 , on day 10 , and day 21 , respectively. Specimens taken on day 35 . Hematoxylin-eosin and immunohistochemically staining performed to measure the number of fibroblasts and type III collagen and to observe the epithelialization and inflammation process.

RESULTS: The number of fibroblasts significantly decreased in the second treatment group $(p=0.001)$ and followed by the first group $(p=0.016)$, but no significant decrease found in the third group $(p=0.430)$. The type III collagen decreased significantly in the second treatment group $(p=0.000)$ and followed by the third group $(p=0.019)$, but no significant decrease found in the first group. There was no statistically different number of fibroblast and type II collagen discovered between the controls. Complete epithelialization found in all groups. Furthermore, no ongoing inflammation found in all groups.

(t) of fibroblasts and type III collagen with no healing disruption. The proliferation phase found to be the best time to start the application of topical corticosteroids. application is effective in suppressing inflammation and accelerating the stimulation of keratinocyte migration, suppressing proliferation and hyperproliferation, and improving the remodeling process (differentiation, degradation, and maturation) with its antimitotic effect [1], [2], [3], [4], [5], [6]. This topical application shows better compliance and provides better additional effects. It was cost effective, skin moistened, relatively easy to apply, and had no pain sensation. Japan Burn Wound Guideline Treatment had included corticosteroid 
topical application as a treatment for burn injury and it showed good outcomes [7], [8], [9].

We examined the effect of corticosteroid topical application on the fibroblast and type III collagen expression in the deep dermal burn in this study. We also compared the outcome based on the time of use to find the best timing of its application.

\section{Materials}

\section{Model}

Fifty-four samples of the female New Zealand Rabbits weighing approximately 2500-3000 g had raised and adapted in wire-bottomed cages at $22^{\circ} \mathrm{C}$ with a 12 h light/12 h dark cycle for 3 weeks before the experiment. The casein diet and water were available ad libitum. The study's ethical clearance had granted by the Ethics Committee of our institution and Udayana University Institutional of Animal Care and Use Committee.

Medications
Hydrocortisone $1 \%$.
Instrumentation for burn
A brass rod with $10 \mathrm{~mm}$ in diameter, $8 \mathrm{~cm}$ long,
and $30 \mathrm{~g}$ weight designed as the burn instrument. Additional
loads added to produce $90 \mathrm{~g}$ of the device's weight. Hence,
it provided equal pressure and heat distribution to the skin.

\section{Methods}

After being well-fed and adapted, three $10 \mathrm{~mm}$ deep dermal burn wounds were created for each of the rabbit's ears by heating the brass instrument to $90^{\circ} \mathrm{C}$ in a Scientific Dry Bath Incubator. The instrument placed directly on the flattened ear for $20 \mathrm{~s}$. Three days after created the burn wound (day 3), consistent with current clinical practice, the burn wounds were debrided surgically with a $10 \mathrm{~mm}$ punch biopsy with perichondrium preservation. The right ear applied as the treatment side, while the contralateral ear applied as the control side. Then, the wounds were divided into three groups based on treatment initiation. The treatment groups on the first, second, and third groups treated with hydrocortisone $1 \%$ (2 $\mathrm{mm}$ thickness) on day 3 , day 10 , and day 21 . The wound in the control groups only treated by transparent dressings. On day 35 , the animals were sacrificed, and the wounds were harvested in $10 \%$ formalin and cut into the paraffinembedded section. The staining (hematoxylin-eosin and immunohistochemistry) then observed to compare each treatment and examine the number of fibroblast and type III collagen. Epithelialization and inflammation also descriptively observed. Data were analyzed by the windows statistical software SPSS 24.0. The fibroblast data difference between groups analyzed using ANOVA statistical test. Kruskal-Wallis and post-hoc Mann-Whitney statistical test was applied to analyze the difference of type III collagen data between the groups.

\section{Results}

\section{Effect of topical corticosteroid on number of fibroblast in rabbit's deep dermal burn wound (mean $\pm S D)$}

Table 1 shows that the second group had the highest difference of fibroblast cell number after day $35(475.78 \pm 305.2$ in the treatment and $1087.78 \pm 322.87$ in the control group) with p: 0.001 . It followed by the first group (740 \pm 366.1 in treatment and $1348.89 \pm 566.81$ in the control group) with p: 0.016 . In the third group, the mean of fibroblast number on the treatment and control group was $1103.89 \pm 320.31$ and $1348.89 \pm 404.95$, respectively, with p: 0.43 .

Table 1: The effect of topical corticosteroid application on number of fibroblast in rabbit's deep dermal burn wound per five visual fields with $400 \times$ between treatments and controls in each group

\begin{tabular}{|c|c|c|c|c|}
\hline \multirow[t]{2}{*}{ Group } & \multirow[t]{2}{*}{ Intervention } & Fibroblast & \multirow[t]{2}{*}{ Mean Difference } & \multirow[t]{2}{*}{ p-value } \\
\hline & & Mean \pm SD & & \\
\hline \multirow[t]{2}{*}{1} & Treatment & $740.0 \pm 366.1$ & \multirow[t]{2}{*}{-608.9} & \multirow[t]{2}{*}{$0.016^{*}$} \\
\hline & Control & $1348.9 \pm 566.8$ & & \\
\hline \multirow[t]{2}{*}{2} & Treatment & $475.8 \pm 305.2$ & \multirow[t]{2}{*}{-612} & \multirow[t]{2}{*}{$0.001^{*}$} \\
\hline & Control & $1087 \pm 322.9$ & & \\
\hline \multirow[t]{2}{*}{3} & Treatment & $1103.9 \pm 320.3$ & \multirow[t]{2}{*}{139.4} & \multirow[t]{2}{*}{0.43} \\
\hline & Control & $964.4 \pm 404.9$ & & \\
\hline
\end{tabular}

Table 2 reveals that the second group had the highest difference of fibroblast cells on the deep dermal burns of rabbit ears after day 35 . The difference between the second group's treatment with the first group's treatment was not statistically significant, but a comparison done with the third group's treatment showed statistically significant results with $p=0.001$.

Table 2: The highest difference in the number of fibroblasts in rabbit's deep dermal burn wound per five visual fields with $400 \times$ between treatments in each group

\begin{tabular}{llll}
\hline Treatment group & Treatment group & $\mathrm{p}$-value & Mean difference \\
\hline 1 & 2 & 0.104 & 264.2 \\
& 3 & 0.209 & $(-) 363.9$ \\
2 & 1 & 0.104 & $(-) 264.2$ \\
& 3 & $0.001^{*}$ & $(-) 628.1$ \\
3 & 1 & 0.029 & 363.9 \\
& 2 & $0.001^{*}$ & 628.1 \\
\hline${ }^{*} \mathrm{p}<0.05:$ Statistically significant. Effect of topical corticosteroid on number of type III collagen in rabbit's \\
deep dermal burn wound (median \pm iq).
\end{tabular}

Table 3 shows that the number of type III collagen with parametric data on deep dermal burns of rabbit ears after day 35 had the highest number of median differences, 15(10) and 27(0) in control and treatment, respectively, with $\mathrm{p}: 0.000$. It followed by the third group with 24(5) and 27(3) in the treatment 
and control groups, respectively, with p: 0.019. While in the first group, the median of the treatment and control groups was $21(11)$ and $27(5)$, respectively, with p: 0.82 .

Table 3: The effect of topical corticosteroid application on number of type III collagen in rabbit's deep dermal burn wound per five visual fields with $400 \times$ between treatments and controls in each group

\begin{tabular}{llll}
\hline Group & Intervention & Type III collagen & p-value \\
\cline { 2 - 3 } & & Median and interquartile range & \\
\hline 1 & Treatment & $21(11)$ & 0.82 \\
& Control & $27(5)$ & $0.000^{*}$ \\
2 & Treatment & $15(10)$ & \\
& Control & $27(0)$ & $0.019^{*}$ \\
3 & Treatment & $24(5)$ & \\
\hline${ }^{*} \mathrm{p}<0.05:$ Statistically & Control & $27(3)$ &
\end{tabular}
collagen in rabbit's deep dermal burn wound between treatments of each group.

Table 4 shows a statistically significant difference of the number of type III collagen comparison between the treatment groups in each group.

Table 4: Comparison of topical corticosteroid application on number of type III collagen in rabbit deep dermal burn wound per five visual fields with $400 \times$ between treatments in each group

\begin{tabular}{lc}
\hline Group's treatment & p-value \\
\hline 1 & $0.004^{*}$ \\
2 & \\
3 & \\
\hline Descriptive evaluation of epithelialization and existing PMN.
\end{tabular}

Figure 1 reveals a complete epithelialization that occurred in 52 samples without existing inflammatory cells. There were two samples in the control group which not completely epithelialized and had existing PMN infiltration (Figure 2.).

\section{Discussion}

This was an experimental study with a randomized posttest-only control group design that aimed to examine the effect of topical corticosteroid application (hydrocortisone 1\%) on deep dermal burns in rabbits to reduce the number of fibroblasts and collagen type III as a marker of hypertrophic scars. This study

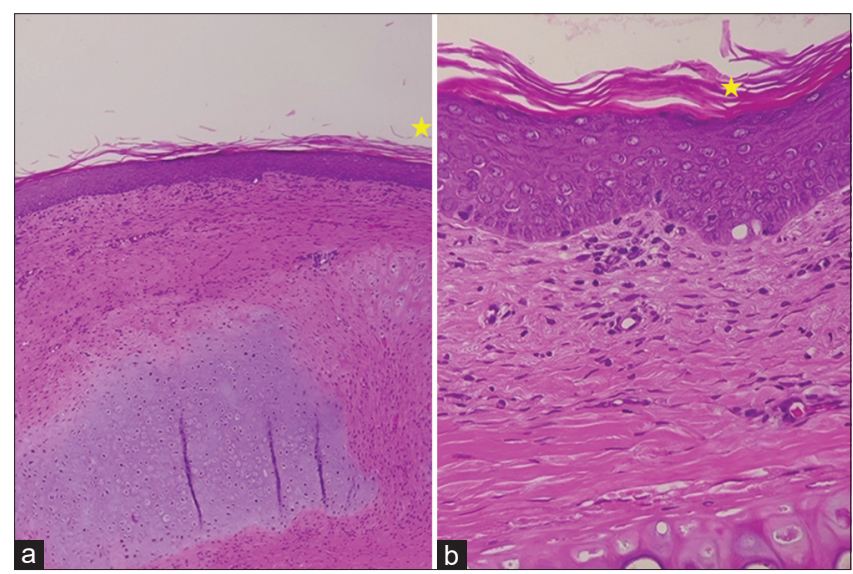

Figure 1: Complete epithelialization (a: 100x; b: 400x)
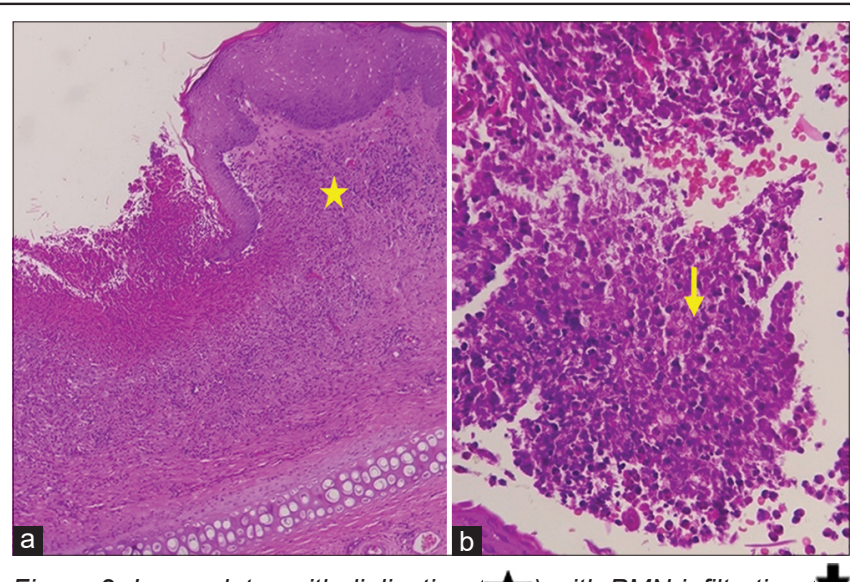

Figure 2: Incomplete epithelialization ) (a: 100x; b: 400x)

also revealed the effect differences on different times of application. Study population randomly classified into three study groups. Each group had three control wounds on the left ears and three treatment wounds on the right ears. Treatment wounds administered topical corticosteroid ointment (hydrocortisone 1\%), while the control ears covered with a transparent dressing only. Corticosteroid application on the wounds conducted 3 times: On day 3 (first treatment group), day 10 (second treatment group), and day 21 (third treatment group). Then, the wound specimens taken on day 35.

The time of application selected according to the peak of each deep dermal wound healing process (inflammation, proliferation, and remodeling) without interfering the healing process itself. In the previous studies, animal trials have shown that corticosteroids administration at least 3 days after a wound happened did not inhibit the wound healing process [10], [11]. Friedrich, 2017, stated that 3 days (day 3) after a deep dermal burn wound formation, the primary necrotic phase had completed and there were significantly upregulated levels of tumor necrosis factor (TNF)- $\alpha$ at this point [12]. TNF- $\alpha$ gene expression is an inflammatory cytokine associated with burn progression and HMGB1 release reduction [11]. Therefore, on day 3 , the inflammation process was about to be completed [12]. On day 28, the same study showed that abundance of new collagens deposited with fine mature collagen (collagen type I). The proliferation phase had been completed, and the remodeling process was also starting to happen at that time. Then, on day 35 , hypertrophic scars with complete epithelialization started to be discovered.

The wound healing process in the human body is different from animal wound healing due to the differences in structure, physiology, and immunology of the skin [13]. Rodents, with loose skin and an underlying panniculus carnosus, heal predominantly by contraction, which makes hypertrophic scar challenging to study, and studies are often limited to a 10-14 days time point at which time there is no measurable scar, so it is often poor models for testing effects on scarring as an endpoint [14]. Pigs may serve as a better model 
for the study of healing and scar formation after burn, but the significant limitation of the pig is the enormously thickened and stiffer skin with the contraction differs from human skin, because of that, the time-to-endpoint can be on the order of months [15]. Rabbits have similar main inflammation cytokine with humans and the closest similarity to human after pig. According to the previous study, hypertrophic scar happened due to deep dermal burns wound also successfully conducted on day 35 at ear of rabbits [12].

Hypertrophic scar is an abnormal scar that results from deep dermal burn wounds. The etiology of hypertrophic scar formation is not fully understood. The factors causing hypertrophic scars associated with burns include the degree and persistence of increased inflammation, burn progression, the depth of the wound, and total burn area. These things cause healing process disruption [16]. It characterized pathologically by the accumulation of both fibroblasts and type III collagen.

Corticosteroids are known as an effective therapy for various types of skin disorders. Several lines of evidence suggest that glucocorticoids alter collagen metabolism in the skin and decrease the proliferation of fibroblast-collagen, also increase the collagenase effect. Topical corticosteroid (hydrocortisone 1\%) elected as the treatment utilized in this study because it was a non-surgical therapeutic modality currently available and has been frequently used for the management of hypertrophic scar caused by hypergranulation in almost all cases of wounds, including deep dermal burn wound, [7], [8], [9], [17]. The occurrence of hypergranulation is consistent with the incidence of abnormal scarring, including hypertrophy [18], [19], [20].

The mean value applied to measure the number of fibroblasts because the data were homogeneous and normally distributed. A significant number of fibroblast reductions considered as the effect of topical corticosteroid application. Application of topical corticosteroids in deep dermal burns that started on day 10 (second group) recognized as the most effective time in reducing the number of fibroblasts (612, $p=0.001)$. The second most effective time of application found in the first group $(p=0.016)$. However, there was no significant difference in fibroblast number in the first and second groups found. The reduction in the number of fibroblasts in this study is in line with the literature on hypertrophy treatment. The ability of corticosteroids to reduce excess fibrous tissue proved by Moio et al., 2014 [21]. It also found to be able in suppressing tissue growth [18], [19], [20], [22].

Contrarily, on the third treatment group (day 21-day 35), the number of fibroblasts was higher than the control grout but was not statistically significant. The different absorption rates in different epidermal thicknesses explained this finding. In the remodeling phase, the raw surface area had been healed and filled with immature epithelialization. The absorption of topical corticosteroids would become lower in comparison with the application on the inflammatory and proliferative phases, which still have raw surface area. Therefore, injection suggested is the only way of administering intralesional corticosteroids [23], [24]. It can also demonstrate that in the remodeling phase, the fibroblasts no longer increase in number, but transform into myofibroblasts. Immature fibroblasts, especially dermal fibroblasts, have larger receptors that are more sensitive to therapeutic modulation. Those reasons explain the absence effect of topical corticosteroids on the remodeling phase [23], [24], [25], [26], [27].

Elevated fibroblast production raised collagen synthesis. This process can lead to collagen build-up if it does not follow by its degradation. Type III collagen also could not be converted into type I that causes hypertrophic scars in the remodeling phase [25], [26], [27].

The median value applied as the collagen type III measurements because the data were not normally distributed. Collagen type III in the controls from each group had similar values, about 27 with a slightly different interquartile range. The median value on the first group, the second group, and the third group was 5,0 , and 3 , respectively. The median score of treatment on Group 1, Group 2, and Group 3 was 21 (11), 15 (10), and 24 (5), respectively. There was a significant difference between treatment and control of the second and third groups, where the second group showed the lowest type III collagen value. Significant differences also found in treatments of each group comparisons $(p=0.004)$.

This result can be explained by the proliferation of productor cells (fibroblasts) decreasing significantly at best in the proliferation phase so that their production (collagen type III) also significantly decreases. This result is in line with Uva et al. and Coondoo et al. that found the role of corticosteroids (anti-mitotic effect) in the dermis inhibits cell proliferation and collagen synthesis [28], [29]. The highest reduction of the amount of type III collagen occurred in the proliferation phase group, followed by the reduction in the remodeling phase group. The effect of topical corticosteroids not only able affects collagen synthesis but also the degradation of type III collagen. In the remodeling phase, there was no decrease in the number of fibroblasts, so the decrease in the amount of type III collagen was also not as high as the one that started in the proliferation phase where the number of fibroblasts, as a productor of type III collagen synthesis, also decreased. Hence, it is clear that corticosteroids play a role in increasing the degradation of type III collagen [25], [26], [27]. This finding is in line with other studies. It found that corticosteroids strongly interfere collagen synthesis and degradation, corticosteroids drastically against type III collagen by reducing tropocollagen levels from collagen type III [30]. Corticosteroids also have a significant impact on type III fibrils of collagen. In 1982, glucocorticoids reported able not only to decrease the 
synthesis of collagen both type I and type III collagen, but it also found changed the ratio of procollagen type III to procollagen type I in rat skin fibroblasts [31]. This finding explains that the change of type III procollagen to type I procollagen is not due to different synthesis regulatory processes, This finding explained that the change of type III procollagen to type I procollagen happened due to the result of extracellular processes and selective extracellular degradation of it.

The administration of corticosteroid was not significantly affected the amount of type III collagen in the inflammatory phase. The application of corticosteroids in the inflammation phase suppressed the PMN immune cells that result in cell function deterioration, which results in a longer inflammatory phase. It proven by the higher number of fibroblasts in the inflammatory group treatment than in the proliferation group [33], [34], [35]. Therefore, the amount of collagen type III in this burn group was higher. But, the statistical analysis identified no significant difference in the number of collagen type III compared to the control group. This finding was in line with a previous study by Todoroki et al. that stated that the use of topical steroids should be limited to the $1^{\text {st }}$ day after injury to $1^{\text {st }}$ or $2^{\text {nd }}$ degree burns because these drugs delay wound healing and suppress epithelialization [36]. In 2014, Taheri proposed topical corticosteroid application after epithelialization to limit persistent inflammation in the dermis, which would be responsible for excess fibroblasts and collagen, leading to hypertrophy [36], [37]. There have been three RCTs (including a double-blind trial) showing that topical corticosteroids have no anti-inflammatory effect on burns [38], [39], [40].

However, these study findings were contrary to results from several studies and expert opinions. Yoshino et al. stated that topical steroids in burns could apply with the recommended level: $\mathrm{C} 1$, as written in a guideline in 2016 for burn management [8]. Topical corticosteroid administration in burns also had widely implemented in Japan. These findings recorded, but it is still an expert opinion about the effectiveness of topical corticosteroids in burn wounds.

Corticosteroids are often associated with wound healing disorders and infections. In this study, almost all wounds in experiment animals had covered microscopically with complete epithelialization on day 35. We identified only one inflamed sample from control that had not fully epithelized. Furthermore, there was a sample that was completely epithelialized but still inflamed. These samples were the control group's sample. These findings are consistent with several studies that found acute use did not cause systemic effects (3-4 weeks) and had no significant influences on the incidence of dehiscence and wound healing [41], [42], [43]. Topical use of low potent could apply for chronic intermittent [44]. A systemic or local injection has no significant effect on wound healing disorders [45]. Side effects reported so far are side effects of systemic and prolonged administration of corticosteroids [45], [46]. Chowdri found that in intraoperative administration of corticosteroids, a complete symptom improvement was achieved in all patients within 5 weeks after surgery. The objective response in terms of no recurrence noted in $91.9 \%$ of patients with keloids and $95.24 \%$ of patients with hypertrophic scars with a mean follow-up of 30.5 months. Local or systemic complications also concluded as insignificant [47].

Based on the results, topical corticosteroid application starting from day 10 was the best timing selected in reducing the number of fibroblasts and type III collagen to prevent hypertrophic wounds on deep dermal burns.Our findings also had indicated that the topical administration of topical corticosteroids (hydrocortisone 1\%) initiated on the proliferation phase provided better hypertrophic scars prevention on deep dermal burns, compared to its administration initiated in the inflammatory (day 3) and remodeling phase (day 21). Topical corticosteroids have shown the ability to assist wound closure and prevent hypertrophic scars in deep dermal burns by reducing the number of fibroblasts in line with the decrease of collagen type III synthesis and increasing the degradation of type III collagen. These findings supported by the study of Guo and DiPietro [48] and Hofman et al. [20] that found that the application of low-dose topical corticosteroids for the treatment of chronic wounds and hypergranulation wounds has been found to accelerate wound healing, accelerate epithelialization, reduce pain and wound exudate, and suppress hypergranulation tissue formation, especially if it prevents the occurrence of infection [20], [48]. The use of low potent corticosteroid (hydrocortisone 1\%) too early in deep dermal burns potentially causes prolonged inflammation. It also found that deviant or excessive inflammation was associated with the incidence of hypertrophic scarring [49], [50], [51].

\section{Conclusions}

Application of topical corticosteroids in deep dermal burn wound effectively reduced the number of fibroblasts and type III collagens. Application in the proliferation phase showed the most effective decrease of the number of fibroblasts and type III collagens. Further studies necessary to be conducted to examine: (1) The mechanism of topical corticosteroids in limiting the inflammatory and abnormal fibrotic response without impeding the wound healing process (the corticosteroid potential, the dose, and duration), (2) the extent of deep dermal burns that can be treated without causing negative effects (local or systemic), (3) possibility to matrix modulation components of corticosteroids, (4) the role of corticosteroids in ECM (extracellular matrix) 
apoptosis without causing scar atrophy, (5) detailed characterization of fibroblasts in scar tissue, and (6) combination of anti-inflammatory with antibiotics and antifungals. These findings could complement the unstudied variables, such as local and systemic infection markers, myofibroblasts, $\alpha$-sm-actin expression, PCNA expression, hyaluronic acid, apoptosis, and p53 levels.

\section{References}

1. Bigliardi PL. Specific stimulation of migration of human keratinocytes by muopiate receptor agonists. J Recept Signal Transduct Res. 2002;22(1-4):9-191. PMid: 12503615

2. Akasaka Y. Basic fibroblast growth factor in an artificial dermis promotes apoptosis and inhibits expression of a-smooth muscle actin, leading to reduction of wound contraction. Wound Rep Regen. 2007;15(3):378-89. https://doi. org/10.1111/j.1524-475x.2007.00240.x

PMid: 17537125

3. Rook JM, McCarson KE. Delay of cutaneous wound closure by morphine via local blockade of peripheral tachykinin release. Biochem Pharmacol. 2007;74(5):7-752. https://doi. org/10.1016/j.bcp.2007.06.005

PMid:17632084

4. Xie JL. Basic fibroblast growth factor (BFGF) alleviates the scar of the rabbit ear model in wound healing. Wound Rep Regen. 2008;16:576-81. https://doi. org/10.1111/j.1524-475x.2008.00405.x

\section{PMid: 18638277}

5. Tiede S. Basic fibroblast growth factor: A potential new therapeutic tool for the treatment of hypertrophic and keloid scars. Ann Anat. 2008;191:33-44. https://doi.org/10.1016/j. aanat.2008.10.001

PMid:19071002

6. Rook JM. Morphine-induced early delays in wound closure: Involvement of sensory neuropeptides and modification of neurokinin receptor expression. Biochem Pharmacol. 2009;77(11):55-1747. https://doi.org/10.1016/j.bcp.2009.03.003 PMid:19428329

7. Ogawa R, Akita S, Akaishi S, Aramaki-Hattori N, Dohi T, Hayashi T, et al. Diagnosis and treatment of keloids and hypertrophic scars-Japan scar workshop consensus document 2018. Burns Trauma. 2019;7:39. https://doi.org/10.1186/ s41038-019-0175-y

PMid:31890718

8. Yoshino Y, Ohtsuka M. The wound/burn guidelines-6: Guidelines for the management of burns. J Dermatol. 2016;43(9):989-1010. PMid:26971391

9. Ogawa R. The most current algorithms for the treatment and prevention of hypertrophic scars and keloids. Plast Reconstr Surg. 2010;125(2):557-68. https://doi.org/10.1097/ prs.0b013e3181c82dd5

PMid:20124841

10. Sandberg N. Time relationship between administration of cortisone and wound healing in rats. Acta Chir Scand. 1964;127:55-446.

PMid: 14169773

11. Fiuza C, Bustin M, Talwar S, Tropea M, Gerstenberger E, Shelhamer JH, et al. Inflammation-promoting activity of HMGB1 on human microvascular endothelial cells. Blood. 2003;101(7):2652-60. https://doi.org/10.1182/ blood-2002-05-1300 PMid: 12456506

12. FriedrichEE. Thermalinjurymodelinthe rabbitearwith quantifiable burn progression and hypertrophic scar. Wound Repair Regen. 2017;25(2):327-37. https://doi.org/10.1111/wrr.12518 PMid:28370931

13. Van den Broek LJ. Human hypertrophic and keloid scar models: Principles, limitations and future challenges from a tissue engineering perspective. Exp Dermatol. 2014;23(6):6-382. https://doi.org/10.1111/exd.12419 PMid:24750541

14. Domergue S, Jorgensen C, Noel D. Advances in research in animal models of burn-related hypertrophic scarring. J Burn Care Res. 2015;36(5):e259-66. https://doi.org/10.1097/ bcr.0000000000000167 PMid:25356852

15. Cuttle L. A porcine deep permal partial thickness burn model with hypertrophic scarring. Burns. 2006;32(7):20-806. https:// doi.org/10.1016/j.burns.2006.02.023 PMid:16884856

16. Mace JE. Differential expression of the immunoinflammatory response in trauma patients: Burn vs. Non-burn. Burns. 2012;38(4):599-606. https://doi.org/10.1016/j. burns.2011.10.013 PMid:22103986

17. Goutos I, Ogawa R. Steroid tape: A promising adjunct to scar management. Scars Burns Heal. 2017;3:9-1. https://doi. org/10.1177/2059513117690937

18. Mcshane D, Bellet J. Treatment of hypergranulation tissue with high potency topical corticosteroids in children. Pediatr Dermatol. 2012;29(5):675-8. https://doi. org/10.1111/j.1525-1470.2012.01724.x PMid:22612258

19. Shalom A, Wong L. Treatment of hypertrophic granulation tissue with topical steroids: 141. J Burn Care Res. 2003;24:S113. https://doi.org/10.1097/00004630-200303002-00141

20. Hofman D. Use of topical corticosteroids on chronic leg ulcers. J Wound Care. 2007;16(5):227-230. https://doi.org/10.12968/ jowc.2007.16.5.27047 PMid: 17552408

21. Moio M. Treatment of hypergranulation tissue with intralesional injection of corticosteroids: Preliminary results. J Plast Reconstr Aesthet Surg. 2014;67(6):e167-8. https://doi.org/10.1016/j. bjps.2014.03.017

PMid:24725728

22. Mandrea E. Topical diflorasone ointment for treatment of recalcitrant, excessive granulation tissue. Dermatol Surg. 1998;24(12):1409-10. https://doi.org/10.1111/j.1524-4725.1998. tb00024.x PMid:9865213

23. Arno AL. Up-to-date approach to manage keloids and hypertrophic scars: A useful guide. Burns. 2014;40(7):1255-66. https://doi.org/10.1016/j.burns.2014.02.011 PMid:24767715

24. Atiyeh BS. Nonsurgical management of hypertrophic scars: Evidence-based therapies, standard practices, and emerging methods. Aesthetic Plast Surg. 2007;1:468-92. https://doi. org/10.1007/s00266-006-0253-y PMid:17576505

25. Backdahl MS. The role of collagenase in wound healing. In: Collagenases. Texas: RG Landes Company; 1999. p. 207-20.

26. Perdanakusuma DS, Noer MS. Penanganan Parut Hipertrofi 
Dan Keloid. Surabaya: Airlangga University Press; 2006.

27. Oskeritzian CA. Mast cells and wound healing. Adv Wound Care (New Rochelle). 2006;1(1):23-8. https://doi.org/10.1089/ wound.2011.0357

PMid:24527274

28. Uva L. Mechanism of action of topical corticosteroids in psoriasis. Int J Endocrinol. 2012;2012:561018. https://doi. org/10.1155/2012/561018

PMid:23213332

29. Coondo A. Side-effect of tropical steroids: A long overdue revisit. Indian Dermatol Online J. 2014;5(4):416-25 https://doi. org/10.4103/2229-5178.142483

PMid:25396122

30. OishiY.Molecularbasisofthealterationinskincollagenmetabolism in response to in vivo dexamethasone treatment: Effects on the synthesis of collagen Type I and III, collagenase, and tissue inhibitors of metalloproteinases. Br J Dermatol. 2002;147(5):58868. https://doi.org/10.1046/j.1365-2133.2002.04949.x PMid:12410694

31. Verbruggen LA, Abe S. Glucocorticoids alter the ratio of Type III/Type I collagen synthesis by mouse dermal fibroblasts. Biochem Pharmacal. 1982;31:1711-5. https://doi. org/10.1016/0006-2952(82)90673-6

32. Shull S. Glucocorticoids change the ratio of Type III to Type I procollagen extracellularly. Coll Relat Res. 1986;6(3):295-300. https://doi.org/10.1016/s0174-173x(86)80013-9 PMid:3769424

33. Gosain A, DiPietro LA. Aging and wound healing. World J Surg. 2004;28(3):321-6. https://doi.org/10.1007/s00268-003-7397-6 PMid:14961191

34. Broughton $G$. The basic science of wound healing. In: Barbul A, editor. Retraction of Witte. Plastic and Reconstructive Surgery. Vol. 77. United States: Lippincott Williams and Wilkins; 2006. p. 509-28.

35. Campos AC. Assessment and nutritional aspect of wound healing. Curr Opin Clin Nutr Metab Care. 2008;11(3):281-8. PMid:18403925

36. Todoroki T. From daily inquiry-adrenal corticosteroid. J Pract Pharm. 1988;39:1085-93.

37. Taheri A. Are corticosteroids effective for prevention of scar formation after second-degree skin burn? J Dermatol Treat. 2014;25(4):360-2. PMid:23688200

38. Pedersen JL. Topical glucocorticoid has no antinociceptive or anti-inflammatory effect in thermal injury. $\mathrm{Br} \mathrm{J}$ Anaesth. 1994;72(4):379-82. https://doi.org/10.1093/bja/72.4.379 PMid:8155434

39. Faurschou A. Topical corticosteroids in the treatment of acute sunburn a randomized, double-blind clinical trial. Arch Dermatol. 2008;144(5):620-4. https://doi.org/10.1001/archderm.144.5.620
PMid:18490588

40. Muramatsu T, Sekiguchi T. The clinical use of corticosteroid ointment for acute second degree burn. Jpn J Plast Surg. 1972;15:318.

41. Schulze S. Effect of prednisolone other systemic response and wound healing after colonic surgery. Arch Surg. 1997;132(2):129-35. https://doi.org/10.1001/ archsurg.1997.01430260027005

PMid:9041914

42. Nicholson G. Perioperative steroid supplementation. Anaesthesia. 1998;53(11): 1091-104.

PMid:10023279

43. Brown CJ, Buie WD. Perioperative stress dose steroids: Do they make a difference? J Am Coll Surg. 2001;193(6):678-86.

PMid:11768685

44. Drake LA. Guidelines of care for the use of topical glucocorticosteroids. American academy of dermatology. J Am Acad Dermatol. 1996;35(4):615-9. https://doi.org/10.1016/ s0190-9622(96)90690-8

PMid:8859293

45. Wang AS. Corticosteroids and wound healing: Clinical considerations in the perioperative period. Am J Surg. 2013;206(3):410-7. https://doi.org/10.12669/pjms.35.2.553 PMid:23759697.

46. Meseci E. Assessment of topical corticosteroid ointment on postcesarean scars prevention: A prospective clinical trial. Pak J Med Sci. 2019;35(2):309-14.

PMid:31086506

47. Chowdri NA. Keloids and hypertrophic scars: Results with intraoperative and serial postoperative corticosteroid injection therapy. Aust N Z J Surg. 1999;69(9):9-655. https://doi. org/10.1046/j.1440-1622.1999.01658.x

PMid:10515339

48. Guo S, DiPietro LA. Factors affecting wound healing. J Dent Res. 2010;89(3):219-29. https://doi.org/10.1177/0022034509359125 PMid:20139336

49. ShihB.Moleculardissection ofabnormalwoundhealing processes resulting in keloid disease. Wound Repair Regen. 2010;18(2):53139. https://doi.org/10.1111/j.1524-475x.2009.00553.x PMid:20002895

50. Curran TA, Ghahary A. Evidence of a role for fibrocyte and keratinocyte-like cells in the formation of hypertrophic scars. J Burn Care Res. 2013;34(2):31-227. https://doi.org/10.1097/ bcr.0b013e318254d1f9

PMid:22955158

51. Tabas I, Glass CK. Anti-inflammatory therapy in chronic disease: Challenges and opportunities. Science. 2013;339(6116):16672. https://doi.org/10.1126/science. 1230720

PMid:23307734 